NASA Technical Memorandum 105178

AIAA-91-3527

\title{
Thermal Emittance Enhancement of Graphite-Copper Composites for High Temperature Space Based Radiators
}

Sharon K. Rutledge

Lewis Research Center

Cleveland, Ohio

and

Mark J. Forkapa and Jill M. Cooper

Cleveland State University

Cleveland, Ohio

Prepared for the

Conference on Advanced Space Exploration Initiative Technologies cosponsored by AIAA, NASA, and OAI

Cleveland, Ohio, September 4-6, 1991 


\title{
THERMAL EMITTANCE ENHANCEMENT OF GRAPHITE-COPPER COMPOSITES FOR HIGH TEMPERATURE SPACE BASED RADIATORS
}

\author{
Sharon K. Rutledge \\ NASA Lewis Research Center \\ Cleveland, Ohio \\ Mark J. Forkapa and Jill M. Cooper \\ Cleveland State University \\ Cleveland, Ohio
}

Abstract

Graphite-copper composites are candidate materials for space based radiators. The thermal emittance of this material, however, is a factor of two lower than the desired emittance for these systems of $\geq 0.85$. Arc texturing has been investigated as a surface modification technique for enhancing the emittance of the composite. Since the outer surface of the composite is copper, and samples of the composite could not be readily obtained for testing, copper was used for optimization testing. Samples were exposed to various frequencies and currents of arcs during texturing. Emittances near the desired goal were achieved at frequencies less than 500 $\mathrm{Hz}$. Arc current did not appear to play a major role under 15 amps. Particulate carbon was observed on the surface which was easily removed by vibration and handling. In order to determine morphology adherence, ultrasonic cleaning was used to remove the loosely adherent material. This reduced the emittance significantly. Emittance was found to increase with increasing frequency for the cleaned samples up to $500 \mathrm{~Hz}$. The highest emittance achieved on these samples over the temperature range of interest was 0.5-0.6 which is approximately a factor of 25 increase over the untextured copper emittance.

\section{Introduction}

Space and surface nuclear power systems will require radiators which can efficiently reject waste heat at elevated temperatures to maintain the desired operating conditions while keeping the area and thus the mass of the radiator acceptably low for launch. Typical radiator operating temperatures are 700-900 $\mathrm{K}$ for thermoelectric systems and 525-650 K for Stirling engine systems. The greatest heat transfer is achieved when the surface acts like a blackbody radiator ${ }^{1}$. The measure of how closely a surface resembles a perfect blackbody radiator is the thermal emittance, where a perfect blackbody is 1.0 on a scale of 0.0 to 1.0. For space radiator systems the thermal emittance desired is $\geq 0.85$. Graphite-copper composites, which are one of the radiator fin materials under consideration because of their light weight and thermal conduction, have an emittance which is a factor of two lower than the desired emittance for both operating temperature ranges. Application of a thermal control paint to the surface can increase the emittance, however, the adherence of the paint would be of concern at high temperature. Another technique for improving the emittance is to alter the surface morphology of the material. For a

\footnotetext{
"Copyright c 1991 by the American

Institute of Aeronautics and Astronautics,

Inc. No copyright is asserted in the United

States under Title 17, U.S. Code. The U.S.

Government has a royalty-free license to

exercise all rights under the copyright

claimed herein for Governmental Purposes.

All other rights are reserved by the

copyright owner."
} 
diffusely reflecting surface, the hemispherical spectral emittance is in general equal the absorptance at the same wavelength ${ }^{1}$. Therefore, by making the roughness on the surface greater than the wavelength of the incident radiation, multiple reflections should occur resulting in a greater absorptance and higher thermal emittance. A technique of this type should eliminate adherence problems because the emittance enhancement is an integral part of the surface. Several techniques for thermal emittance enhancement of metals have been explored ${ }^{2-4}$; the most promising to date is arc texturing. This paper discusses the use of arc texturing as a technique to improve the thermal emittance of graphite-copper radiator surfaces through surface morphology alteration.

\section{Apparatus and Procedure}

Graphite-Copper Composites: Graphitecopper composites for these tests were fabricated in the Materials Division of NASA Lewis Research Center. Samples were fabricated by arc spraying P-100 graphite fibers with copper to form monotapes which were layered with a final thin face sheet of copper applied to each side. Due to the small number of samples that were available for testing, copper sheet $0.025 \mathrm{~cm}$ thick was used to simulate the composite for optimization tests since the outer surface only is affected by the texturing technique. Samples of copper were punched to $2.38 \mathrm{~cm}$ diameter for testing. The graphite-copper was cut by wire electric discharge machining to the same diameter.

Emittance Measurement: Total emittance at $322 \mathrm{~K}$ was measured with a Gier Dunkle model DB 100 Reflectometer. The spectral hemispherical emittance was measured using both a Perkin Elmer Lambda-9 UV-VIS-NIR Spectrophotometer (250-2500 nm) and a Hohlraum Reflectometer (1500-15,000 nm). By overlapping the results from both instruments, the reflectance as a function of wavelength was obtained for each sample. Since the samples are not transmissive, the spectral hemispherical emittance, which is equivalent to the spectral hemispherical absorptance at any wavelength could be obtained by subtracting the value for reflectance at a given wavelength from unity. The total hemispherical emittance at a given temperature was then obtained by normalizing the spectral emittance data with respect to the blackbody curve at the temperature of interest using equation (1).

$$
\epsilon\left(T_{A}\right)=\frac{\int_{\lambda=250}^{15,000} \epsilon_{\lambda}\left(\lambda, T_{A}\right) \epsilon_{\lambda b}\left(\lambda, T_{A}\right) d \lambda}{\sigma T_{A}{ }^{4}}
$$

The Hohlraum Reflectometer and the integration technique are discussed in more detail in reference 4.

Arc Texturing: A spectroscopic grade carbon electrode of $6.35 \mathrm{~mm}$ diameter in a water cooled holder was used to generate an arc between it and the radiator surface. Both were electrically connected so that the arc completed the circuit path as shown in figure 1.

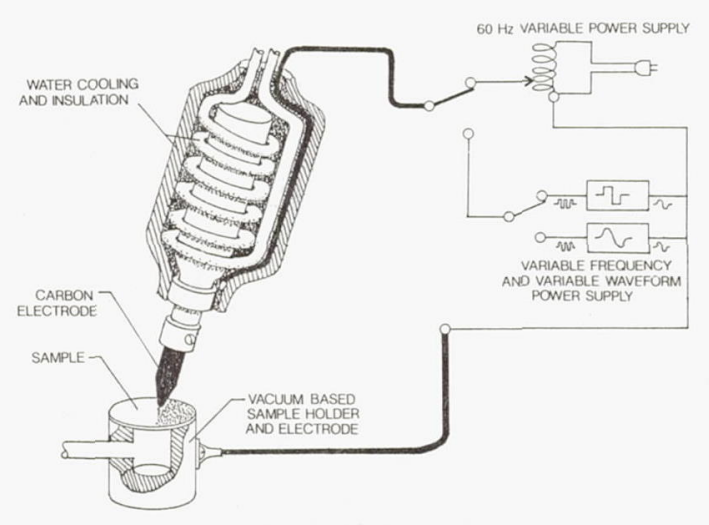

Fig. 1. Arc texturing apparatus 
Typical texturing currents ranged from 10 to 20 amperes AC. Frequency was varied between 20 and $10,000 \mathrm{~Hz}$. A variable transformer was used for texturing at $60 \mathrm{~Hz}$ and a Powertron 2505 $\mathrm{HF}$ variable frequency power supply was used for the remainder of the texturing. The arc is drawn manually across the surface using a wand. The arc melts both the surface and the carbon electrode at the arc site which resolidifies when cooled. The surface after arc texturing is no longer smooth but contains pits and peaks which allow high spectral emittance over the infrared wavelength ranges. In addition to surface roughening, carbon from the electrode is also incorporated into the metal surface when it resolidifies. This gives the surface a black appearance and also aids in emittance enhancement. Due to the darkening of the surface during texturing, determination of adequate arc texturing could be made visually.

Texturing was performed inside a glove box so that the environment surrounding the sample could be purged with nitrogen gas for at least 4 hours prior to texturing. During texturing, a gas flow of 200-280 SCCM of argon was blown over the sample so to reduce surface oxidation during texturing. Samples were held to the electrical contact plate with vacuum produced by a small roughing pump (100-200 $\mu \mathrm{m})$.

\section{Results and Discussion}

Copper arc textured at various

frequencies and currents exhibited a marked improvement in thermal emittance over untextured copper. One example of this is shown in figure 2 .

In general, there is an increase in thermal emittance with temperature. Between 10 and 13 amps of AC texturing current, there did not seem to be a significant difference in thermal emittance at a specific temperature. The changes observed were within the 0.05 exror of the emittance measurement instruments.

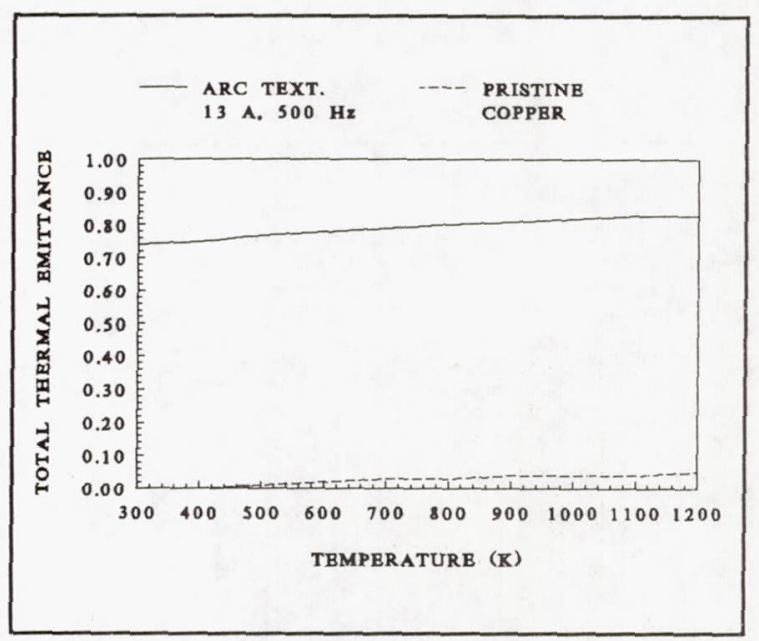

Fig. 2. A comparison of the total emittance vs temperature for untextured copper and copper arc textured at 13 amps, $500 \mathrm{~Hz}$.

Thermal emittance appeared constant with frequency for frequencies less than $100 \mathrm{~Hz}$ and decreased slightly between 500 and $10,000 \mathrm{~Hz}$. The results of the frequency and current testing at two different temperatures approximating the center of the thermoelectric and Stirling power system regimes is contained in figure 3 .

Due to the limitations of the variable frequency power supply, arc texturing currents above 13 amps could not be achieved. In order to extend the current range, a variable transformer at $60 \mathrm{~Hz}$ was used to achieve currents up to 20 amps. No significant arcing was observed at currents below 10 amps at $60 \mathrm{~Hz}$. Figure 4 contains the results of the arc texturing as a function of current at $60 \mathrm{~Hz}$ for copper. Thermal emittance was recorded at 322 and $1159 \mathrm{~K}$ using the DB 100 Reflectometer and Perkin Elmer Lambda-9 spectrophotometer since the Hohlraum Reflectometer was unavailable at this time. 


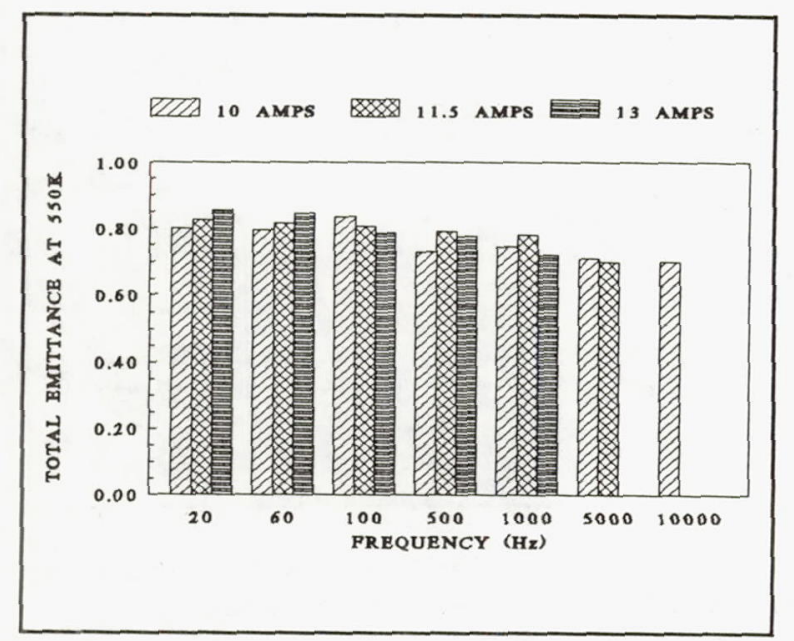

a.

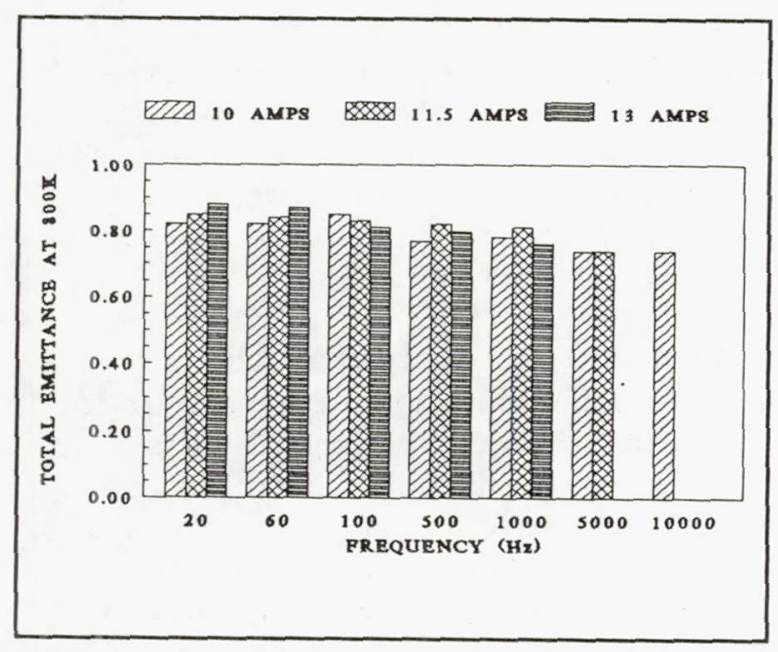

b.

Fig. 3. Total emittance as a function of frequency and current for arc textured copper at a). $550 \mathrm{~K}$ and b). $800 \mathrm{~K}$

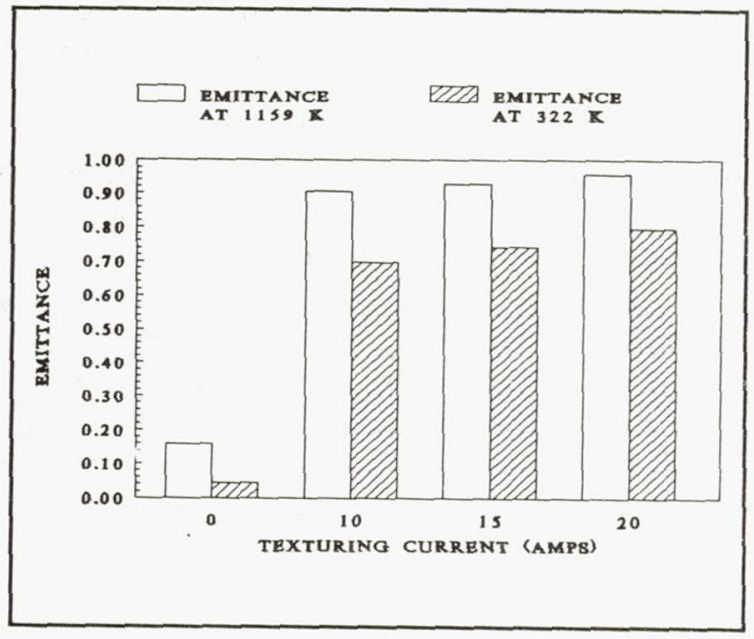

Fig. 4. Thermal emittance of arc textured copper as a function of current at $60 \mathrm{~Hz}$.

There appeared to be a slight increase in thermal emittance between 10 and 20 amperes for arc textured copper. It appears that frequencies below $100 \mathrm{~Hz}$ and currents of approximately 15 to 20 amps will provide the highest thermal emittance for arc textured copper. However at 20 amps the copper begins to warp, so lower currents would be more desirable. Similar tests were preformed for the graphite-copper composite samples at a texturing frequency of $60 \mathrm{~Hz}$ as shown in figure 5 .

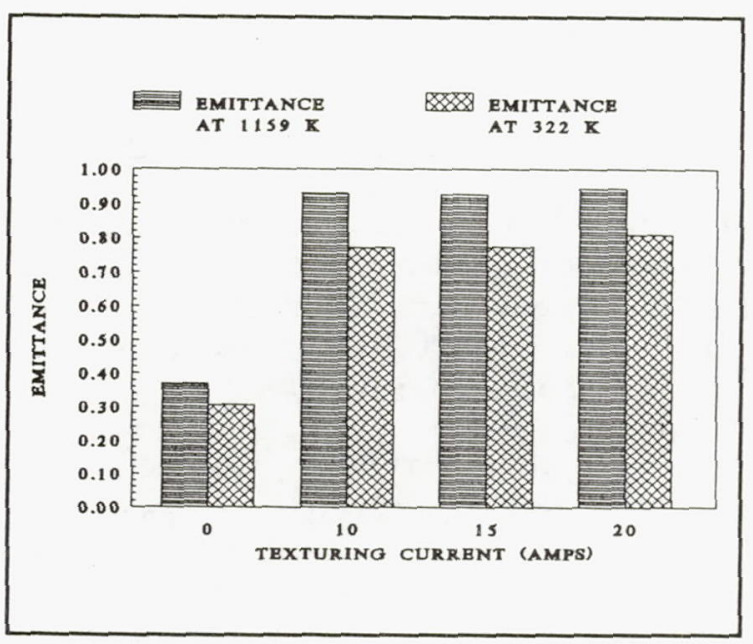

Fig. 5. Total emittance as a function of texturing current for arc textured graphite-copper composites. 
Although the initial thermal emittance of the composite is higher than that for copper, the emittance after texturing is very similar which indicates that the texture of the surface is becoming a dominant factor in determining the thermal emittance. Even less change in emittance with texturing current is observed for the composite. The similarity of the data indicates that the results from copper emittance optimization can be used to determine the optimum conditions for the less available composite. The thermal emittances achieved for both the copper and graphite-copper composite arc textured samples are very close to the thermal emittance goal of 0.85 in the power system temperature ranges of interest.

Samples textured at frequencies below $100 \mathrm{~Hz}$ were found to leave carbon residue in their sample containers. Also, particulate carbon was very easily removed from the surface by handling or vibration. This indicated that at least part of the carbon on the surface was not well adhered. This is of serious concern because of possible loss of carbon due to vibration during launch which may result in system contamination or loss in thermal emittance. Adherence of the carbon to the surface was determined by ultrasonically cleaning each sample arc textured at one current level and various frequencies in a beaker of water for 5 minutes and observing the thermal emittance following this exposure. Figure 6 contains the thermal emittances at 550 and $800 \mathrm{~K}$ for arc textured copper at 10 amps.

Although there was a minor change in emittance with frequency for the textured samples, there was a significant change with frequency for those which were ultrasonically cleaned. It appears that the most adherent surface is produced at approximately $500 \mathrm{~Hz}$. Samples at higher frequencies produced lower emittances after cleaning. Scanning electron microscope (SEM) photos taken with a
JOEL SEM of the copper after arc texturing shows much particulate on the surface (fig. 7). It is believed that the particles dominate the emittance measurement in the temperature range of interest.

After ultrasonic cleaning, the particulate is removed and the arc pits and incorporated carbon are much more visible. As seen in figure 8 , the depth of the arc pits and the amount of incorporated carbon appear to increase for frequencies up to 500 $\mathrm{Hz}$. This may account for the increase in emittance.

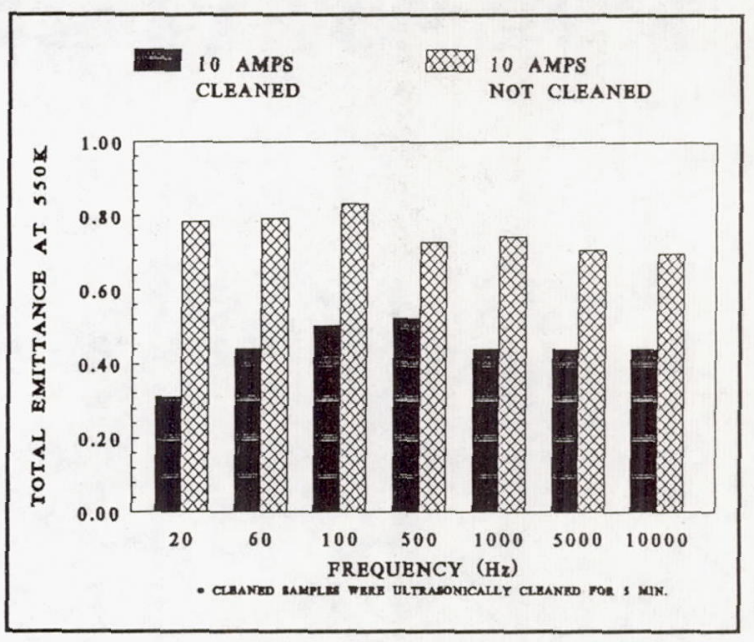

a.

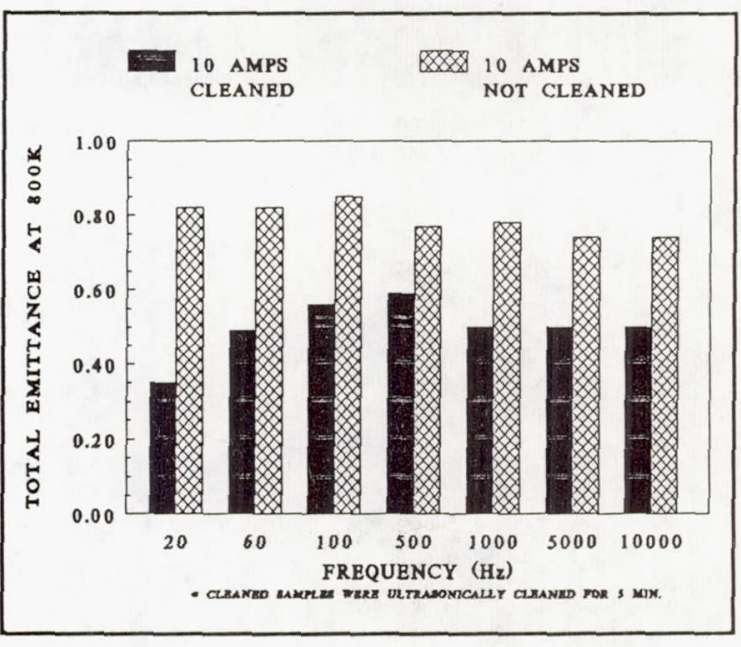

b.

Fig. 6. Comparison of total emittance at a.) $550 \mathrm{~K}$ and b). $800 \mathrm{~K}$ 
for copper arc textured at 10 amps, both uncleaned and ultrasonically cleaned

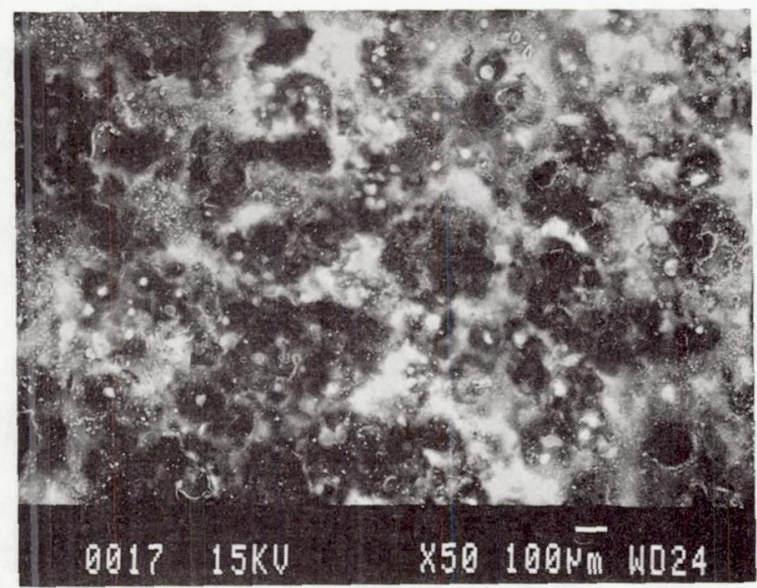

Fig. 7. Typical copper arc textured surface
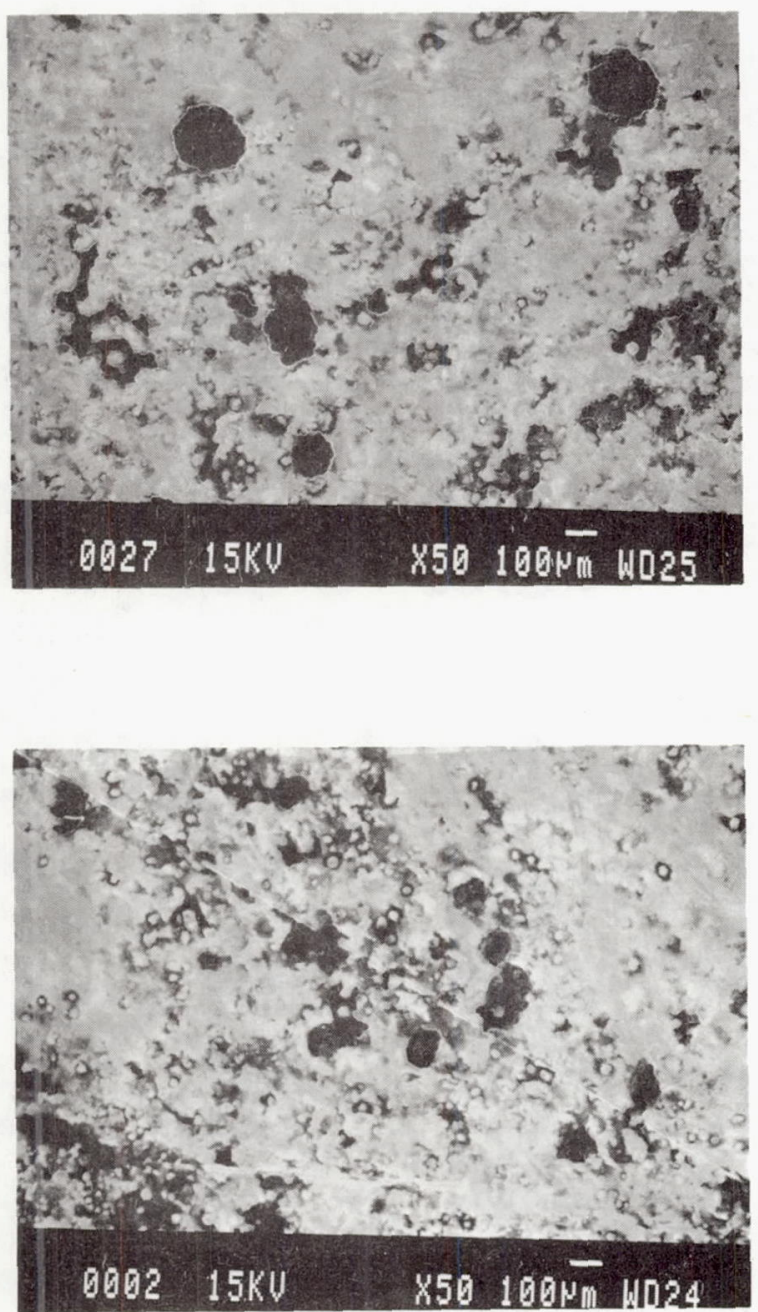
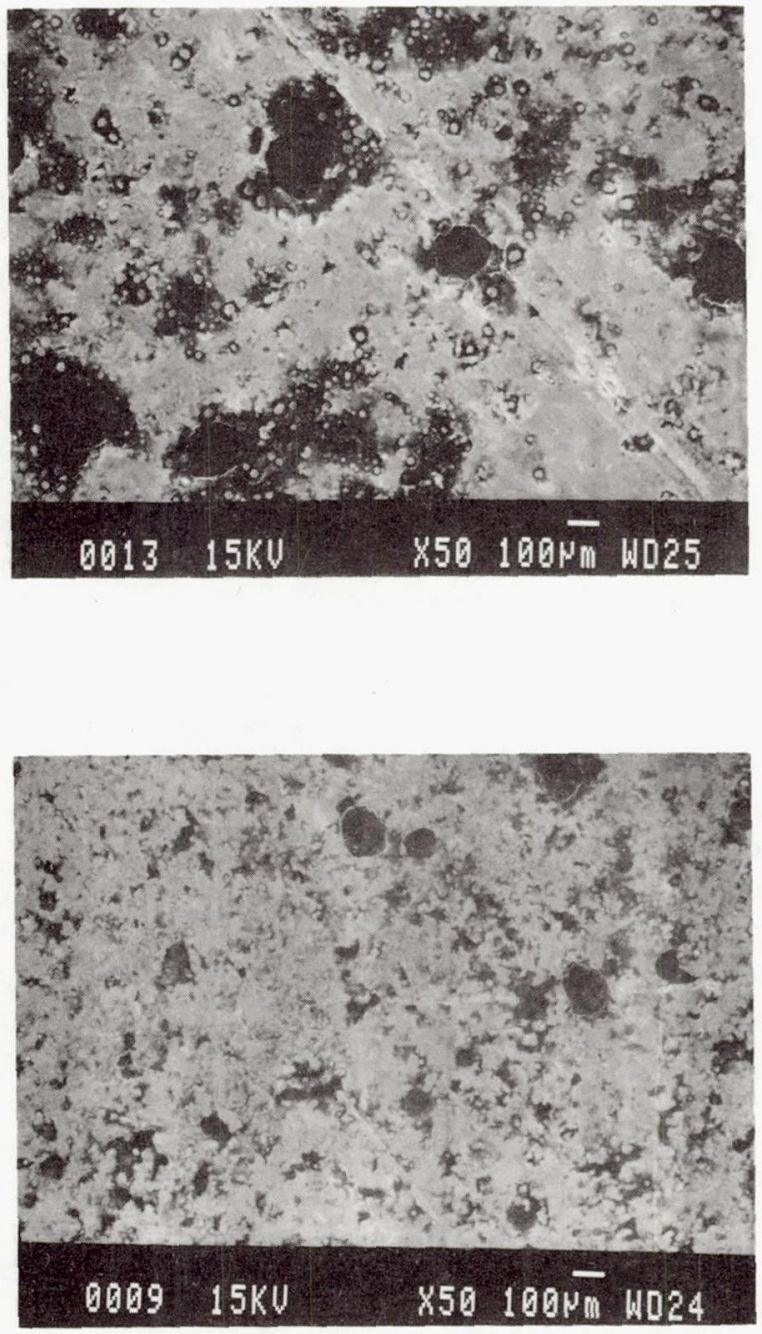

Fig. 8. Scanning Electron Microscope (SEM) photographs of copper arc textured at a). $20 \mathrm{~Hz}$, b). $60 \mathrm{~Hz}$, c). $500 \mathrm{~Hz}$, and d). $5,000 \mathrm{~Hz}$ then ultrasonically cleaned.

It has been theorized that the arc pressure increases with frequency up to $5000 \mathrm{~Hz}$ which can make the molten pool at the arc site spread ${ }^{5}$. It is possible that beyond $500 \mathrm{~Hz}$, the pool spreads too much making the roughness less pronounced. At frequencies greater than $5000 \mathrm{~Hz}$, it is believed that the arc pressure reaches a limit ${ }^{5}$. This would account for the 
constant emittance at higher

frequencies. Energy dispersive x-ray analysis performed with a Kevex system on these samples indicated only copper at the center of the arc pit with a surrounding area consisting primarily of carbon, silicon, and sulfur. On examination of the electrode, it was found that the electrode contained silicon and sulfur in addition to carbon. Therefore, the surrounding region appears to be composed of the electrode material. Figure 9 contains an enlarged view of one of the arc pits.

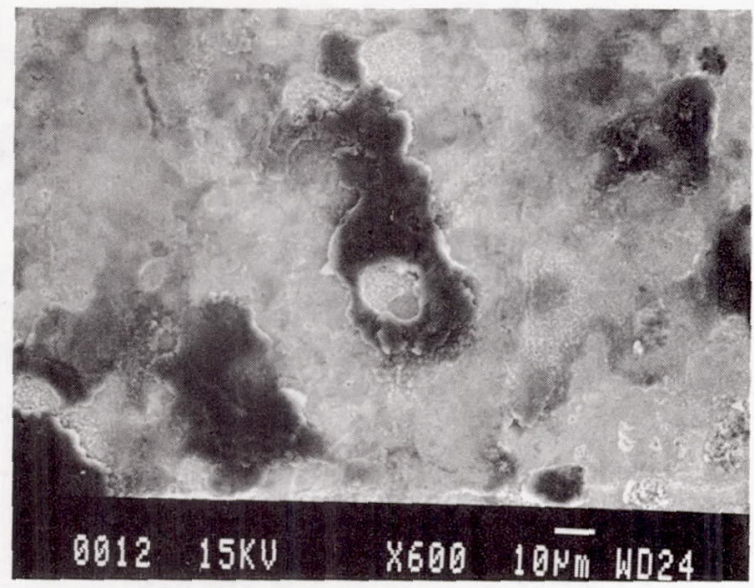

Fig. 9. Typical arc pit in copper

These results indicate that frequencies greater than $100 \mathrm{~Hz}$ but less than 1000 $\mathrm{Hz}$ are needed in order to produce high emittance surfaces which are durable. The effect of current on durability has not yet been determined. The maximum emittance achieved after cleaning was 0.5 to 0.6 which is a factor of approximately 25 improvement over the untextured samples, however more work needs to be performed with regard to electrode material and current levels to achieve a durable surface with $a \geq$ 0.85 thermal emittance level.

\section{Conclusions}

Arc texturing can produce greater than a factor of two increase in thermal emittance for copper and graphitecopper composites. Emittance enhancement appears to be produced by particulate carbon, arc pits, and carbon incorporated into the copper surface. Adherence of the morphology which produces emittance enhancement appears to be strongly dependent on the frequency of the arc used to texture the surface. Frequencies between 100 and $1000 \mathrm{~Hz}$ appear to provide the most durable samples to vibration and handling. Samples with 0.5 to 0.6 thermal emittance can be achieved in the operating temperature ranges of interest, however more research into current effects and electrode composition needs to be performed in order to attempt to reach the desired $\geq 0.85$ thermal emittance goal.

\section{$\underline{\text { References }}$}

1. Siegal, R. and Howell, J.R.; Thermal Radiation Heat Transfer, Second Edition, Mc Graw Hill, 1981.

2. Rutledge, S.K. et al.; High Temperature Radiator Materials for Applications in the Low Earth Orbital Environment, NASA TM-100190, 1987.

3. Banks, B.A. et al.; Arc Textured Metal Surfaces for High Thermal Emittance Space Radiators, NASA TM-100894, 1988.

4. Mirtich, M.J. and Kussmaul, M.T.; Enhanced Thermal Emittance of Space Radiators by Ion Discharge Chamber Texturing, NASA TM-100137, 1987.

5. Cook, G.E.; El Bean, H., and Eassa, E.H.; "The Effect of High Frequency Pulsing of a Welding Arc," IEEE Transactions on Industry Applications, Vol. 1A 21 , No. 5 , September/October, 1985. 
Public reporting burden for this collection of information is estimated to average 1 hour per response, including the time for reviewing instructions, searching existing data sources, gathering and maintaining the data needed, and completing and reviewing the collection of information. Send comments regarding this burden estimate or any other aspect of this collection of information, including suggestions for reducing this burden, to Washington Headquarters Services, Directorate for information Operations and Reports, 1215 Jefferson Davis Highway, Suite 1204, Arlington, VA 22202-4302, and to the Office of Management and Budget, Paperwork Reduction Project (0704-0188), Washington, DC 20503.

\begin{tabular}{|l|l|l}
\hline 1. AGENCY USE ONLY (Leave blank) & 2. REPORT DATE & $\begin{array}{r}\text { 3. REPORT TYPE AND DATES COVERED } \\
\text { Technical Memorandum }\end{array}$ \\
\hline
\end{tabular}

\section{TITLE AND SUBTITLE}

Thermal Emittance Enhancement of Graphite-Copper Composites for High

Temperature Space Based Radiators

5. FUNDING NUMBERS

Sharon K. Rutledge, Mark J. Forkapa, and Jill M. Cooper

WU $-590-13-11$

6. AUTHOR(S)

7. PERFORMING ORGANIZATION NAME(S) AND ADDRESS(ES)

National Aeronautics and Space Administration

Lewis Research Center

Cleveland, Ohio 44135-3191

8. PERFORMING ORGANIZATION REPORT NUMBER

E- 6475

\section{SPONSORING/MONITORING AGENCY NAMES(S) AND ADDRESS(ES)}

National Aeronautics and Space Administration

Washington, D.C. 20546-0001
10. SPONSORING/MONITORING AGENCY REPORT NUMBER

NASA - TM - 105178

AIAA - 91- 3527

11. SUPPLEMENTARY NOTES

Prepared for the Conference on Advanced Space Exploration Initiative Technologies cosponsored by AIAA, NASA, and OAI, Cleveland, Ohio, September 4-6, 1991. Sharon K. Rutledge, NASA Lewis Research Center; Mark J. Forkapa and Jill M. Cooper, Cleveland State University, Cleveland, Ohio 44115. Responsible person, Sharon K. Rutledge, (216) 433-2219.

12a. DISTRIBUTION/AVAILABILITY STATEMENT

12b. DISTRIBUTION CODE

Unclassified - Unlimited

Subject Category 27

13. ABSTRACT (MaxImum 200 words)

Graphite-copper composites are candidate materials for space based radiators. The thermal emittance of this material, however, is a factor of two lower than the desired emittance for these systems of $\geq 0.85$. Arc texturing has been investigated as a surface modification technique for enhancing the emittance of the composite. Since the outer surface of the composite is copper, and samples of the composite could not be readily obtained for testing, copper was used for optimization testing. Samples were exposed to various frequencies and currents of arcs during texturing. Emittances near the desired goal were achieved at frequencies less than $500 \mathrm{~Hz}$. Arc current did not appear to play a major role under 15 amps. Particulate carbon was observed on the surface which was easily removed by vibration and handling. In order to determine morphology adherence, ultrasonic cleaning was used to remove the loosely adherent material. This reduced the emittance significantly. Emittance was found to increase with increasing frequency for the cleaned samples up to $500 \mathrm{~Hz}$. The highest emittance achieved on these samples over the temperature range of interest was 0.5-0.6 which is approximately a factor of 25 increase over the untextured copper emittance.

\begin{tabular}{|l|l|}
\hline $\begin{array}{l}\text { 14. SUBJECT TERMS } \\
\text { Emittance; Heat transfer; Radiators }\end{array}$ \\
\hline $\begin{array}{c}\text { 17. SECURITY CLASSIFICATION } \\
\text { OF REPORT } \\
\text { Unclassified }\end{array}$ & $\begin{array}{c}\text { 18. SECURITY CLASSIFICATION } \\
\text { OF THIS PAGE } \\
\text { Unclassified }\end{array}$ \\
\hline
\end{tabular}

\begin{tabular}{|c|c|}
\hline & $\begin{array}{c}\text { 15. NUMBER OF PAGES } \\
8\end{array}$ \\
\hline & $\begin{array}{r}\text { 16. PRICE CODE } \\
\mathrm{A} 02\end{array}$ \\
\hline $\begin{array}{l}\text { 19. SECURITY CLASSIFICATION } \\
\text { OF ABSTRACT } \\
\text { Unclassified }\end{array}$ & 20. LIMITATION OF ABSTRACT \\
\hline
\end{tabular}

